\title{
Effects of properties of the surface layer of seed particles on the formation of golf ball-like polymer particles by seeded dispersion polymerization*
}

\author{
Natsumi Konishi, Teruhisa Fujibayashi, Takuya Tanaka, Hideto Minami and Masayoshi Okubo
}

\begin{abstract}
Micrometer-sized, monodisperse polystyrene (PS)/poly(styrene-co-sodium styrene sulfonate) (P(S-NaSS))/poly( $n$-butyl methacrylate) (Pn-BMA) composite particles having a 'golf ball-like' shape were prepared by seeded dispersion polymerization of $n$-butyl methacrylate with PS-core/P(S-NaSS)-shell seed particles with various shell thicknesses in the presence of dodecane droplets in a methanol/water $(80 / 20$, w/w) medium, followed by evaporation of the dodecane. The effects of the hydrophilic $\mathrm{P}(\mathrm{S}-\mathrm{NaSS})$-shell properties of seed particles on the formation of golf ball-like particles were investigated on the basis of thermodynamic and kinetic considerations. The dimples at the surface formed by the volume reduction of Pn-BMA/dodecane domains were deep when PS/P(S-NaSS) seed particles, the hydrophilic shell of which was thick, were used, whereas PS/P(S-NaSS)/Pn-BMA composite particles, the P(S-NaSS) hydrophilic shell of which was thin, exhibited a polyhedral shape. This is attributed to the fact that the molecular weight of the shell moiety comprising $P(S-N a S S)$ was reduced by lowering the monomer concentration to decrease shell thickness, which seems to result in an increase in the mobility of Pn-BMA/dodecane domains at the particle surface. On the basis of this finding, when the molecular weight of the shell moiety of the seed particle was increased, golf ball-like particles were formed, even if the shell thickness of seed particles was thin.
\end{abstract}

Polymer Journal (2010) 42, 66-71; doi:10.1038/pj.2009.313

Keywords: golf ball-like particle; nonspherical particle; seeded dispersion polymerization

\section{INTRODUCTION}

Nonspherical polymer particles possess anomalous properties compared with spherical particles in terms of crystal structures, ${ }^{1,2}$ light scattering ${ }^{3}$ and rheological features ${ }^{4}$ because of their interesting shape, and can thus be applicable for cosmetics and viscosity-controlling materials. Consequently, a precise design of the particle shape is needed to use these particles in industrial fields. Normally, polymer particles prepared by heterogeneous systems, such as emulsion, dispersion and suspension polymerization, have a spherical shape because of the minimization of the interfacial free energy between the particles and an aqueous medium. However, from the 1970s, the formation of nonspherical polymer particles has been described in studies on the preparation of composite polymer particles by various seeded polymerizations (for example, seeded emulsion polymerization ${ }^{5-19}$ and seeded dispersion polymerization (SDP ${ }^{19-23}$ ). Although they were formed by chance in most cases, their formation mechanisms have been clarified in relation to the morphologies of composite particles, which were determined by a combination of thermodynamic and kinetic factors. ${ }^{24}$

Recently, we proposed a new possibility for the preparation of micrometer-sized monodisperse polymer particles having disk-like, polyhedral and golf ball-like shapes by SDP in the presence of hydrocarbon droplets in methanol/water media. ${ }^{22,23,25}$ The hydrocarbon solvent was predominantly absorbed by the domain comprising the secondary polymer of the composite particles. Nonspherical polymer particles were obtained after evaporation of the hydrocarbon solvent because of a significant volume reduction of the phase comprising the secondary polymer and solvent. Particle shapes were affected by polarity of the seed or secondary polymer, type of hydrocarbon solvent, shaking rate and methanol content in the medium.

In a previous study, ${ }^{26}$ we successfully prepared golf ball-like particles by SDP of $n$-butyl methacrylate ( $n$-BMA) with $1.44 \mu \mathrm{m}$ sized PS-core/P(S-NaSS)-shell (approximately $120 \mathrm{~nm}$ shell thickness) particles as seed in the presence of dodecane droplets in a methanol/ water $(80 / 20, w / w)$ medium, followed by evaporation of the dodecane. On the other hand, composite particles covered with P $n$-BMA having a polyhedral shape were obtained by SDP using hydrophobic PS seed particles (without hydrophilic $\mathrm{P}(\mathrm{S}-\mathrm{NaSS}$ ) shell). These results indicate that one of the key factors for the preparation of nonspherical particles by SDP was relative polarity of the seed polymer to the secondary polymer.

In this paper, the effect of the properties of $\mathrm{P}(\mathrm{S}-\mathrm{NaSS})$ shell on the formation of golf ball-like PS/P(S-NaSS)/Pn-BMA composite particles 
prepared by SDP of $n$-BMA using $\mathrm{PS} / \mathrm{P}(\mathrm{S}-\mathrm{NaSS})$ core/shell seed particles with various shell thicknesses $(20 \mathrm{~nm}-160 \mathrm{~nm})$ is investigated in detail.

\section{EXPERIMENTAL PROCEDURE}

\section{Materials}

Styrene (S) and $n$-BMA were purified by distillation under reduced pressure in a nitrogen atmosphere. Reagent-grade 2,2'-azobisisobutyronitrile (AIBN) (Wako Pure Chemical Industries, Osaka, Japan) was purified by recrystallization with methanol. Water was purified using an Elix UV 3 system (Nihon Millipore KK, Tokyo, Japan). Sodium styrene sulfonate (NaSS) (Wako Pure Chemical Industries), poly( $N$-vinylpyrrolidone) (average molecular weight: $4 \times 10^{4} \mathrm{~g} \mathrm{~mol}^{-1}$ ), methanol, $n$-dodecane and $n$-decane (Nacalai Tesque, Kyoto, Japan) were used as received.

\section{Preparation of PS/P(S-NaSS) core/shell seed particles by SDP} of $S$ and NaSS with PS particles

Monodisperse PS particles were prepared under the optimum dispersion polymerization condition determined in a previous study, ${ }^{26}$ and subsequently, the particles obtained were washed three times by centrifugation with methanol. Next, SDPs of S and NaSS were performed using the obtained PS particles as seed in a methanol/water mixture in sealed glass tubes under a nitrogen atmosphere at $70^{\circ} \mathrm{C}$ for $24 \mathrm{~h}$ under the conditions listed in Table 1 . The tubes were shaken horizontally at 60 cycles $\mathrm{min}^{-1}$ (3-cm strokes) in a water bath. The $\mathrm{PS} / \mathrm{P}(\mathrm{S}-\mathrm{NaSS})$ composite particles obtained were washed three times by centrifugation with methanol. The $\mathrm{PS} / \mathrm{P}(\mathrm{S}-\mathrm{NaSS})$ particles prepared using PS/ (S-NaSS) ratios $(\mathrm{w} / \mathrm{w})$ of $1 / 1,1 / 0.5$ and $1 / 0.1$ were defined as $\mathrm{PS} / \mathrm{P}(\mathrm{S}-\mathrm{NaSS})_{1 / 1}$, $\mathrm{PS} / \mathrm{P}(\mathrm{S}-\mathrm{NaSS})_{1 / 0.5}$ and $\mathrm{PS} / \mathrm{P}(\mathrm{S}-\mathrm{NaSS})_{1 / 0.1}$, respectively. The number-average diameter $\left(D_{\mathrm{n}}\right)$ and coefficient of variation $\left(C_{\mathrm{v}}\right)$ of the seed particles were measured with a transmission electron microscope (TEM) (JEM-1230, JEOL, Tokyo, Japan) using image analysis software (MacSCOPE, Mitani, Fukui, Japan) in a Macintosh computer.

\section{Preparation of $\mathrm{PS} / \mathrm{P}(\mathrm{S}-\mathrm{NaSS}) / \mathrm{P} n$-BMA composite particles by SDP of $n$-BMA in the presence of dodecane}

Seeded dispersion polymerizations of $n$-BMA were performed using PS/P(S$\mathrm{NaSS}$ ) core/shell particles having different shell thicknesses as seed in the presence of dodecane in a methanol/water medium in sealed glass tubes under a nitrogen atmosphere as follows: PS/P(S-NaSS) seed particles $(0.5 \mathrm{~g}), n$-BMA $(0.25 \mathrm{~g})$, AIBN (3 mg), poly( $N$-vinylpyrrolidone) $(0.05 \mathrm{~g})$, methanol $(8 \mathrm{~g})$, water $(2 \mathrm{~g})$ and dodecane $(1 \mathrm{~g})$ were mixed and poured into a glass tube. The glass tubes were sealed under nitrogen, heated at $60{ }^{\circ} \mathrm{C}$, and thereafter shaken horizontally (3-cm strokes) at 60 cycles $\mathrm{min}^{-1}$ for $24 \mathrm{~h}$ in a water bath. Dodecane existed as droplets and as a layer during polymerization, which is partially soluble in the medium $(0.65 \mathrm{wt} \%)$. The obtained particles after drying were observed using a scanning electron microscope (SEM) (S-2500, Hitachi Science Systems, Ibaraki, Japan). The dried particles, stained with ruthenium tetraoxide $\left(\mathrm{RuO}_{4}\right)$ vapor at room temperature for $30 \mathrm{~min}$ in the presence of a $1 \% \mathrm{RuO}_{4}$ aqueous solution, were dispersed in an epoxy matrix that was cured at room temperature for $24 \mathrm{~h}$, and subsequently microtomed and observed using TEM.

\section{The gel-trapping method for the estimation of surface}

\section{hydrophilicity of particles}

To examine the surface hydrophilicity of PS/P(S-NaSS) core/shell particles, the gel-trapping method $^{27}$ was applied as follows: Gellan gum was dissolved in water $\left(2.0 \mathrm{wt} \%\right.$ solution) at $90^{\circ} \mathrm{C}$ for $15 \mathrm{~min}$. $n$-Decane, which was heated at $50^{\circ} \mathrm{C}$ in advance, was then poured onto the gellan solution. Thereafter, PS/P (S-NaSS) particles dispersed in a water/2-propanol mixture were gently injected into the interface between the decane and gellan solution phases with a microsyringe. After spreading the particles, it was cooled down to room temperature and left undisturbed for about $30 \mathrm{~min}$ to lead to gelation, which fixed the particles. Subsequently, the decane phase was removed using a pipette and was replaced by poly(dimethylsiloxane) (PDMS) silicone elastomer.
Table 1 Recipe for preparation of PS/P(S-NaSS) core/shell seed particles $^{\mathrm{a}}$

\begin{tabular}{|c|c|c|c|}
\hline \multirow[b]{2}{*}{ Ingredients } & \multicolumn{3}{|c|}{$P S /(S+N a S S)(w / w)$} \\
\hline & $1 / 0.1$ & $1 / 0.5$ & $1 / 1$ \\
\hline PS particles ${ }^{b}(g)$ & 0.5 & 0.5 & 0.5 \\
\hline$S(g)$ & 0.049 & 0.245 & 0.49 \\
\hline NaSS (g) & 0.001 & 0.005 & 0.01 \\
\hline AIBN (g) & 0.01 & 0.01 & 0.01 \\
\hline $\operatorname{PVPc}^{(g)}$ & 0.05 & 0.05 & 0.05 \\
\hline Methanol (g) & 7.8 & 7.8 & 7.8 \\
\hline Water (g) & 1.2 & 1.2 & 1.2 \\
\hline P(S-NaSS) layer thickness ${ }^{d}(\mu \mathrm{m})$ & 0.023 & 0.104 & 0.187 \\
\hline
\end{tabular}

Abbreviations: AIBN, 2,2'-azobis(isobutyronitrile); NaSS, sodium p-styrenesulfonate; PS, polystyrene; P(S-NaSS), poly(styrene-co-sodium styrene sulfonate); PVP, poly(vinyl pyrrolidone); S, styrene.

Preparation of PS/P(S-NaSS) core/shell particles by seeded dispersion polymerization of $S$ and NaSS $(\mathrm{S}-\mathrm{NaSS}=98-2, \mathrm{w}-\mathrm{w}$ ) with PS seed particles at various $\mathrm{PS} /(\mathrm{S}+\mathrm{NaSS})$ ratios. PS/P(S-

NaSS) particles prepared using PS/(S-NaSS) ratios (w/w) of $1 / 1,1 / 0.5$ and $1 / 0.1$ were defined

as PS/P(S-NaSS) $)_{1 / 1}$. PS/P(S-NaSS) $)_{1 / 0.5}$ and PS/P(S-NaSS) $1 / 1,1$, respectively.

as $\mathrm{PS} / \mathrm{P}(\mathrm{S}-\mathrm{NaSS})_{1 / 1}, \mathrm{PS} / \mathrm{P}(\mathrm{S}-\mathrm{NaSS})_{1 / 0.5}$ and $\mathrm{PS} / \mathrm{P}(\mathrm{S}-\mathrm{NaSS})_{1 / 0.1}$,
${ }^{\mathrm{a}} \mathrm{N}_{2} ; 70^{\circ} \mathrm{C} ; 24 \mathrm{~h}$; shaking rate, 60 cycles $\mathrm{min}^{-1}(3 \mathrm{~cm}$ strokes $)$.

Number-average diameter $\left(D_{n}\right): 1.44 \mu \mathrm{m}$; coefficient of variation $\left(C_{v}\right): 8 \%$.

cMolecular weight, 40000 .

${ }^{\mathrm{d} C a l c u l a t e d ~ a s s u m i n g ~} \mathrm{P}(\mathrm{S}-\mathrm{NaSS})$ accumulated completely on PS seed particles.

The samples were left for 3 days, the PDMS elastomer with partially embedded particles was peeled from the gel after setting the PDMS, and observed by SEM.

\section{Molecular weight measurement}

Molecular weight distributions of PS and PS/P(S-NaSS) seed particles were measured by gel permeation chromatography with two S/divinylbenzene gel columns (TOSOH Corporation, Tokyo, Japan, TSKgel GMHHR-H, $7.8 \mathrm{~mm}$ i.d. $\times 30 \mathrm{~cm}$ ) using THF as eluent at $40^{\circ} \mathrm{C}$ at a flow rate of $1.0 \mathrm{ml} \mathrm{min}^{-1}$ using refractive index detection (TOSOH RI-8020/21). The columns were calibrated with six standard PS samples $\left(1.05 \times 10^{3}-5.48 \times 10^{6}, M_{\mathrm{w}} / M_{\mathrm{n}}=1.10-1.15\right)$. The molecular weight distributions of the shell moiety comprising $\mathrm{P}(\mathrm{S}-\mathrm{NaSS})$ were obtained by subtracting the weight distribution $(w(\log M) / M$ vs $M)$ of PS from that of PS/P(S-NaSS), while taking into consideration the polymer composition, calculated from the initial amount of monomer and its conversion using the software VisSim (Version 1.5d, Visual Solutions, Westford, MA, USA).

\section{RESULTS AND DISCUSSION}

Figure 1 shows TEM photographs of PS/P(S-NaSS) composite particles prepared by SDPs of $\mathrm{S}$ and NaSS $(\mathrm{S}-\mathrm{NaSS}=98-2, \mathrm{w}-\mathrm{w})$ with PS seed particles $\left(D_{\mathrm{n}}: 1.44 \mu \mathrm{m}, C_{\mathrm{v}}: 8 \%\right)$ at various $\mathrm{PS} /(\mathrm{S}+\mathrm{NaSS})$ ratios $(1 / 0.1,1 / 0.5$ and $1 / 1(\mathrm{w} / \mathrm{w}))$. The corresponding $D_{\mathrm{n}}$ values $(\mu \mathrm{m})$ were 1.49, 1.59 and 1.76; $C_{\mathrm{v}}$ values (\%) were 2.90, 6.41 and 6.35; and $\mathrm{P}(\mathrm{S}-\mathrm{NaSS})$ shell thicknesses $(\mathrm{nm})$ were 18,75 and 155 , respectively. The increased diameters were, respectively, consistent with the corresponding calculated values from the initial amount of monomer and its conversion as shown in Table 1 . Our previous studies ${ }^{28-30}$ indicated that SDP is one of the most useful methods for the preparation of core-shell particles, because a secondary polymer formed in a medium accumulated on seed particles in which viscosity is extremely high. In addition, because $\mathrm{P}(\mathrm{S}-\mathrm{NaSS})$ has a higher affinity to the methanol/ water $(87 / 13$, w/w) medium than PS, the obtained PS/P(S-NaSS) particles should have a core-shell structure.

Figures $2 \mathrm{a}-\mathrm{c}$ shows SEM photographs of $\mathrm{PS} / \mathrm{P}(\mathrm{S}-\mathrm{NaSS}) / \mathrm{P} n-\mathrm{BMA}$ composite particles prepared by SDPs of $n$-BMA, with PS/P(S-NaSS) core/shell seed particles having various shell thicknesses in the presence of dodecane in a methanol/water $(80 / 20$, w/w) medium, followed by evaporation of dodecane, and TEM photographs (Figures $2 \mathrm{a}^{\prime}-\mathrm{c}^{\prime}$ ) of their ultrathin cross-sections of particles after 
$\mathrm{RuO}_{4}$ staining. $\mathrm{RuO}_{4}$ selectively stains $\mathrm{PS}$ and $\mathrm{P}(\mathrm{S}-\mathrm{NaSS})$ but not $\mathrm{P} n$ BMA. The PS/P(S-NaSS)/Pn-BMA composite particles obtained by using $\mathrm{PS} / \mathrm{P}(\mathrm{S}-\mathrm{NaSS})_{1 / 0.1}$ seed particles had a polyhedral shape, whereas those by $\mathrm{PS} / \mathrm{P}(\mathrm{S}-\mathrm{NaSS})_{1 / 1}$ seed particles had a golf ball-like shape. Thus, as the $\mathrm{P}(\mathrm{S}-\mathrm{NaSS})$ content in $\mathrm{PS} / \mathrm{P}(\mathrm{S}-\mathrm{NaSS})$ seed particles was increased, which signifies an increase in $\mathrm{P}(\mathrm{S}-\mathrm{NaSS})$ shell thickness, the number of dimples at the surface of each $\mathrm{PS} / \mathrm{P}(\mathrm{S}-\mathrm{NaSS}) / \mathrm{P} n-\mathrm{BMA}$ composite particle was obviously increased, and in the TEM photograph of ultrathin cross-sections (Figures $2 a^{\prime}-c^{\prime}$ ), the size of dimples decreased with increasing shell thickness. In our previous study, ${ }^{26}$ it was clarified that the shape of $\mathrm{PS} / \mathrm{P}(\mathrm{S}-\mathrm{NaSS}) / \mathrm{P} n$-BMA composite particles prepared by SDP of $n$-BMA in the presence of dodecane using $\mathrm{PS} / \mathrm{P}(\mathrm{S}-\mathrm{NaSS})(1 / 1, \mathrm{w} / \mathrm{w})$ seed particles with various $\mathrm{S}-\mathrm{NaSS}$ ratios of $\mathrm{P}(\mathrm{S}-\mathrm{NaSS})$ (100-0 to 90-10) was influenced by the surface hydrophilicity of PS/P(S-NaSS) seed particles. In this study, in order to prepare seed particles having the same surface hydrophilicity, the SDP of $\mathrm{S}$ and NaSS with PS particles was carried out at the same S-NaSS ratio $(98-2, w-w)$. However, $\mathrm{PS} / \mathrm{P}(\mathrm{S}-\mathrm{NaSS}) / \mathrm{P} n$-BMA had different shapes when $\mathrm{PS} / \mathrm{P}(\mathrm{S}-\mathrm{NaSS})$ seed particles with various $\mathrm{P}(\mathrm{S}-\mathrm{NaSS})$ shell thicknesses were used. This result might be caused by decreasing the surface hydrophilicity of PS/P(S-NaSS) seed particles because of
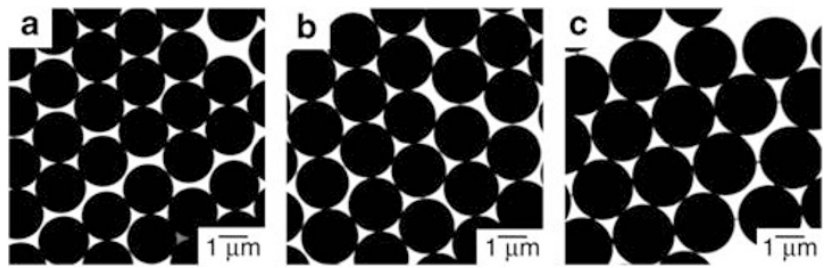

Figure $1 \mathrm{PS} / \mathrm{P}(\mathrm{S}-\mathrm{NaSS})$ seed particles having various compositions. Transmission electron microscope photographs of PS/P(S-NaSS) composite particles prepared by SDPS of $\mathrm{S}$ and NaSS (S-NaSS $=98-2$, w-w) with PS seed particles at various $\mathrm{PS} /(\mathrm{S}+\mathrm{NaSS}$ ) ratios $(\mathrm{w} / \mathrm{w})$ : (a) $1 / 0.1$; (b) $1 / 0.5$; (c) $1 / 1$. partial mixing between PS core and $\mathrm{P}(\mathrm{S}-\mathrm{NaSS})$ shell. Therefore, the surface hydrophilicities of seed particles were estimated as follows.

Figure 3 shows SEM photographs indicating the exposed parts of $\mathrm{PS} / \mathrm{P}(\mathrm{S}-\mathrm{NaSS})$ seed particles that correspond to those embedded in the gellan gum gel for the estimation of surface hydrophilicity by the gel-trapping method. ${ }^{27}$ The volume of exposure of the particles indicates the degree of hydrophilicity of seed particle surfaces (see Experimental procedure). The surface of the $\mathrm{PS} / \mathrm{P}(\mathrm{S}-\mathrm{NaSS})_{1 / 0.1} \quad(\mathrm{~S}-\mathrm{NaSS}=98-2$, $\mathrm{w}-\mathrm{w})$ particle (Figure $3 \mathrm{~b}$ ) was more hydrophobic than that of PS/ $\mathrm{P}(\mathrm{S}-\mathrm{NaSS})_{1 / 1}(\mathrm{~S}-\mathrm{NaSS}=98-2, \mathrm{w}-\mathrm{w})$ particles (Figure 3a). This suggests that the NaSS content in the thinnest shell of $\mathrm{PS} / \mathrm{P}(\mathrm{S}-\mathrm{NaSS})_{1 / 0.1}$ particles was decreased by partial mixing between PS core and P(SNaSS) shell. That is, this seemed to be the reason why golf ball-like PS/ $\mathrm{P}(\mathrm{S}-\mathrm{NaSS}) / \mathrm{P} n$-BMA composite particles could not be prepared when using $\mathrm{PS} / \mathrm{P}(\mathrm{S}-\mathrm{NaSS})_{1 / 0.1}(\mathrm{~S}-\mathrm{NaSS}=98-2, \mathrm{w}-\mathrm{w})$. To confirm this point, the NaSS content was increased at the same thin shell thickness. As shown in Figure 3c, the surface hydrophilicity of the obtained PS/P $(\mathrm{S}-\mathrm{NaSS})_{1 / 0.1}(\mathrm{~S}-\mathrm{NaSS}=80-20, \mathrm{w}-\mathrm{w})$ particles prepared under the conditions listed in Table 2 was the same as that of $\mathrm{PS} / \mathrm{P}(\mathrm{S}-\mathrm{NaSS})_{1 / 1}$ seed particles (S-NaSS $=98-2, \mathrm{w}-\mathrm{w}$ ) (Figure 3a). However, the SDP of $n$-BMA with $\mathrm{PS} / \mathrm{P}(\mathrm{S}-\mathrm{NaSS})_{1 / 0.1}(\mathrm{~S}-\mathrm{NaSS}=80-20, \mathrm{w}-\mathrm{w})$ seed particles resulted in polyhedral $\mathrm{PS} / \mathrm{P}(\mathrm{S}-\mathrm{NaSS}) / \mathrm{P} n$-BMA composite particles (Figure 4) that were similar to the particles (Figures 2a, $\mathrm{a}^{\prime}$ ) prepared using $\mathrm{PS} / \mathrm{P}(\mathrm{S}-\mathrm{NaSS})_{1 / 0.1}(\mathrm{~S}-\mathrm{NaSS}=98-2, \mathrm{w}-\mathrm{w})$ seed particles, contrary to our expectation.

In our previous studies, ${ }^{23,25}$ SDPs of 2-ethylhexyl methacrylate with PS seed particles in methanol/water media were carried out in the presence of various saturated hydrocarbons, and revealed that the shape of particles obtained was influenced by the type of hydrocarbon, shaking rate and methanol content of the media. In these cases, low viscosity within PS seed particles increased the mobility of the domain comprising the secondary polymer and the hydrocarbon and accelerated the coalescence of domains in the surface layer, resulting in different nonspherical particles. That is, the particle shape was governed by the viscosity within PS seed particles, which was influenced by the hydrocarbon adsorption rate. In this study, the kind of
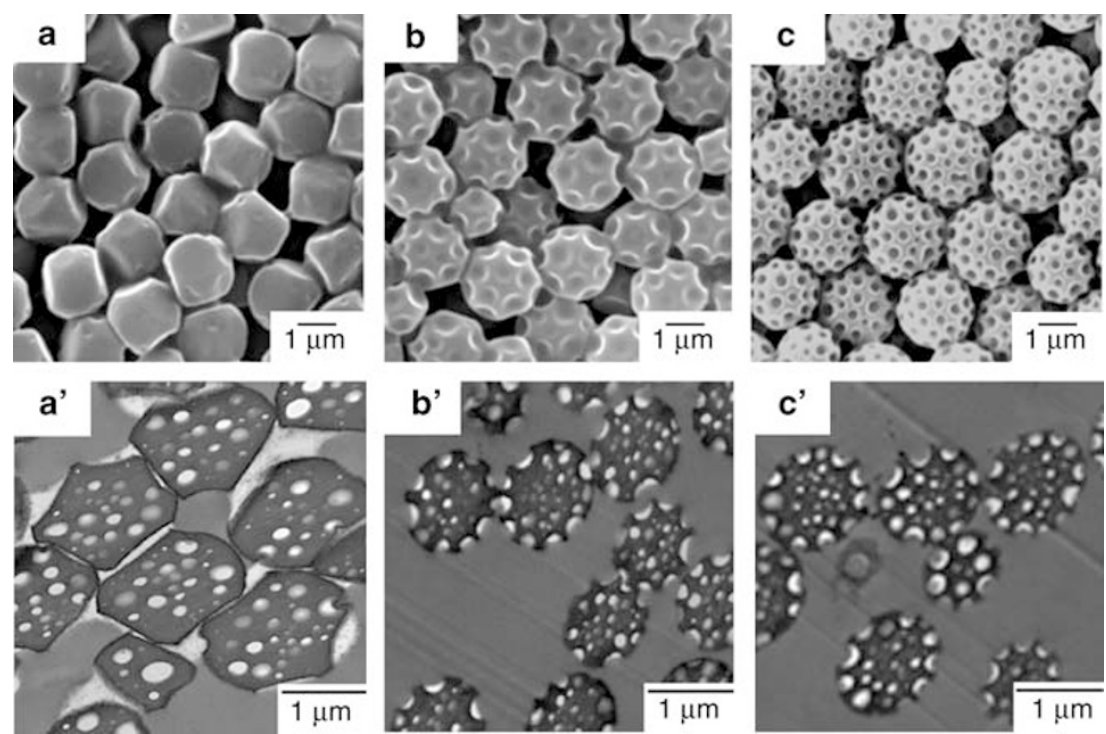

Figure 2 PS/P(S-NaSS)/Pn-BMA composite particles. Scanning electron microscope photographs (a-c) of PS/P(S-NaSS)/Pn-BMA seed particles prepared by SDPs of $n$-BMA in the presence of dodecane droplets in a methanol/water $(80 / 20$, w/w) medium with PS/P(S-NaSS) $1 / 0.1$ (a), PS/P(S-NaSS) $1 / 0.5$ (b) or PS/P $\left(\mathrm{S}-\mathrm{NaSS}_{1 / 1}\right.$ (c) (S-NaSS $=98-2, \mathrm{w}-\mathrm{w}$ ) seed particles, and transmission electron microscope photographs (a' $\left.-\mathbf{c}^{\prime}\right)$ of ultrathin cross-sections of composite particles after staining with $\mathrm{RuO}_{4}$. 

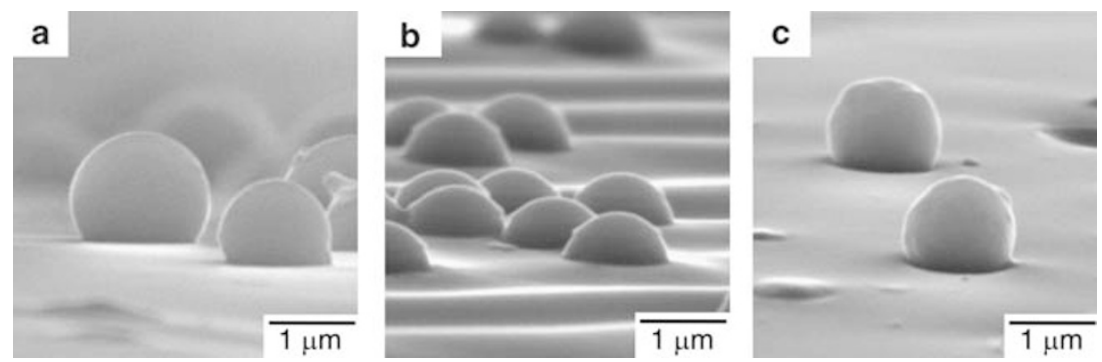

Figure 3 Estimation of surface hydrophilicity of PS/P(S-NaSS) seed particles by the gel-trapping method. Scanning electron microscope photographs of exposed PS/P(S-NaSS) seed particles: (a) PS/P(S-NaSS) $1 / 1$ (S-NaSS =98-2, w-w); (b) PS/P(S-NaSS) $)_{1 / 0.1}(\mathrm{~S}-\mathrm{NaSS}=98-2, \mathrm{w}-\mathrm{w}) ;(\mathbf{c}) \mathrm{PS} / \mathrm{P}(\mathrm{S}-\mathrm{NaSS})_{1 / 0.1}$ $(\mathrm{S}-\mathrm{NaSS}=80-20, \mathrm{w}-\mathrm{w})$. The volume of exposed parts corresponds to that of embedded ones in a gellan gum gel in the gel-trapping method, which depends on the degree of surface hydrophilicity of seed particles.

Table 2 Recipes for preparation of PS/P(S-NaSS) core/shell seed particles having different molecular weights of $\mathrm{P}(\mathrm{S}-\mathrm{NaSS})^{\mathrm{a}}$

\begin{tabular}{lllll}
\hline & \multicolumn{4}{c}{ AlBN (mmol $\left.{ }^{-1}\right)$} \\
\cline { 2 - 5 } Ingredients & 0.055 & 0.11 & 0.55 & 1.1 \\
\hline PS particles $^{\mathrm{b}}$ (g) & 0.5 & 0.5 & 0.5 & 0.5 \\
$\mathrm{~S}$ (g) & 0.04 & 0.04 & 0.04 & 0.04 \\
NaSS (g) & 0.01 & 0.01 & 0.01 & 0.01 \\
AlBN (g) & 0.0005 & 0.001 & 0.005 & 0.01 \\
PVPc (g) & 0.05 & 0.05 & 0.05 & 0.05 \\
Methanol (g) & 7.8 & 7.8 & 7.8 & 7.8 \\
Water (g) & 1.2 & 1.2 & 1.2 & 1.2 \\
\hline
\end{tabular}

Abbreviations: AIBN, 2,2'-azobis(isobutyronitrile); NaSS, sodium p-styrenesulfonate; PS, polystyrene; $\mathrm{P}(\mathrm{S}-\mathrm{NaSS})$, poly(styrene-co-sodium styrene sulfonate); PVP, poly(vinyl pyrrolidone), S, styrene.

Preparation of PS/P(S-NaSS) seed particles by seeded dispersion polymerization of $\mathrm{S}$ and NaSS (S-NaSS $=80-20, w-w)$ with PS seed particles at various AIBN concentrations.

${ }^{a} \mathrm{~N}_{2} ; 70^{\circ} \mathrm{C} ; 24 \mathrm{~h}$; shaking rate, 60 cycles $\mathrm{min}^{-1}$ ( $3 \mathrm{~cm}$ strokes).

${ }^{b}$ Number-average diameter $\left(D_{n}\right): 1.44 \mu \mathrm{m}$; coefficient of variation $\left(C_{1}\right): 8 \%$ cMolecular weight, 40000 .
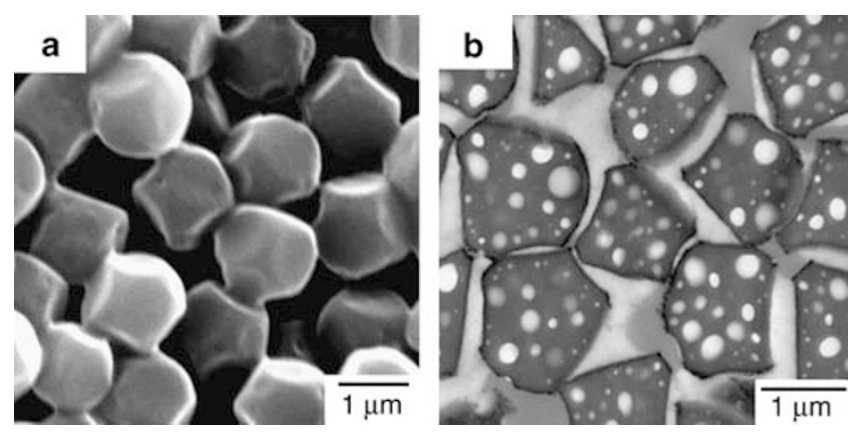

Figure $4 \mathrm{PS} / \mathrm{P}(\mathrm{S}-\mathrm{NaSS}) / \mathrm{P} n-\mathrm{BMA}$ composite particles $(\mathrm{PS} /(\mathrm{S}+\mathrm{NaSS})=1 / 0.1$, $\mathrm{w} / \mathrm{w} ; \mathrm{S}-\mathrm{NaSS}=80-20, \mathrm{w}-\mathrm{w})$. Scanning electron microscope photograph (a) of PS/P(S-NaSS)/P $n$-BMA composite particles prepared by SDP of $n$-BMA in the presence of dodecane droplets in a methanol/water $(80 / 20, \mathrm{w} / \mathrm{w})$ medium with $\mathrm{PS} / \mathrm{P}(\mathrm{S}-\mathrm{NaSS})_{1 / 0.1}(\mathrm{~S}-\mathrm{NaSS}=80-20$, w-w) seed particles, and transmission electron microscope photograph (b) of ultrathin cross-sections of composite particles after $\mathrm{RuO}_{4}$ staining.

hydrocarbon, shaking rate and methanol content of the medium were the same in all SDPs. On the other hand, molecular weight should also be considered as an important factor while determining the viscosity of seed particles and the mobility of $\mathrm{P} n$-BMA/dodecane domains. ${ }^{31-33}$
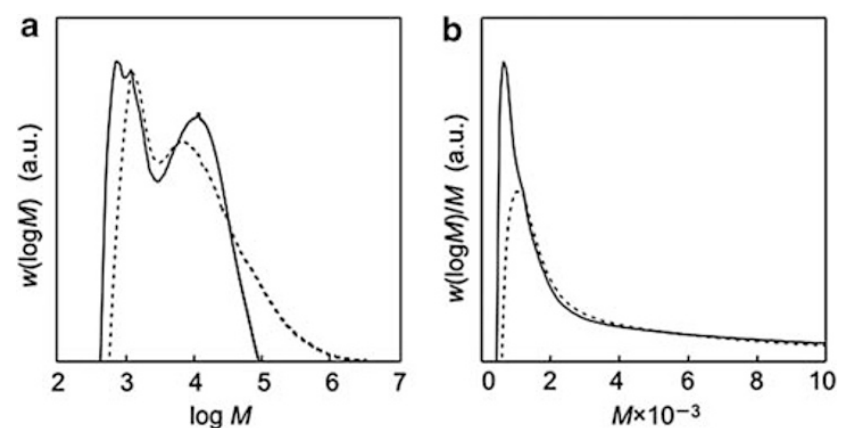

Figure 5 Molecular weight distributions (MWDs) and number distributions of $\mathrm{P}(\mathrm{S}-\mathrm{NaSS}$ ). (a) MWDs and (b) number distributions (area normalized to unity) of $\mathrm{P}(\mathrm{S}-\mathrm{NaSS})$ in PS/P(S-NaSS) seed particles: (-) PS/P(S-NaSS) $)_{1 / 1}$ $(\mathrm{S}-\mathrm{NaSS}=98-2, \mathrm{w}-\mathrm{w}) ;(-)$ PS/P(S-NaSS $)_{1 / 0.1}(\mathrm{~S}-\mathrm{NaSS}=80-20, \mathrm{w}-\mathrm{w})$.

Figure 5 shows molecular weight distributions of $\mathrm{P}(\mathrm{S}-\mathrm{NaSS})$ in PS/ $\mathrm{P}(\mathrm{S}-\mathrm{NaSS})$ particles, which were estimated by subtracting the weight distribution $(w(\log M) / M$ vs $M)$ of PS from that of $\mathrm{PS} / \mathrm{P}(\mathrm{S}-\mathrm{NaSS})$, while considering polymer composition. The fraction of the low molecular weight of $\mathrm{P}(\mathrm{S}-\mathrm{NaSS})$ in $\mathrm{PS} / \mathrm{P}(\mathrm{S}-\mathrm{NaSS})_{1 / 0.1}(\mathrm{~S}-\mathrm{NaSS}=80$ $20, \mathrm{w}-\mathrm{w})$ seed particles was larger than that of $\mathrm{PS} / \mathrm{P}(\mathrm{S}-\mathrm{NaSS})_{1 / 1}$ $(\mathrm{S}-\mathrm{NaSS}=98-2, \mathrm{w}-\mathrm{w})$. This may be caused by a decrease in monomer concentration for the preparation of $\mathrm{PS} / \mathrm{P}(\mathrm{S}-\mathrm{NaSS})_{1 / 0.1}$ seed particles. There was no difference in molecular weight between $\mathrm{P}$ (S-NaSS) (98-2 and $80-20, \mathrm{w}-\mathrm{w})$ in the two kinds of $\mathrm{PS} / \mathrm{P}(\mathrm{S}-\mathrm{NaSS})_{1 / 0.1}$ particles (data not shown). In SDP, polymerization mainly proceeds in a medium and then at the surface of seed particles after adsorption by them. Therefore, molecular weight should be decreased with decreasing monomer concentration, and this might induce an increase in the mobility of the shell part, which would accelerate the coalescence of $\mathrm{P} n$-BMA/dodecane domains, resulting in polyhedral particles.

To prepare golf ball-like $\mathrm{PS} / \mathrm{P}(\mathrm{S}-\mathrm{NaSS}) / \mathrm{P} n$-BMA composite particles using $\mathrm{PS} / \mathrm{P}(\mathrm{S}-\mathrm{NaSS})_{1 / 0.1}$ seed particles, the initiator concentration in the SDP of S and NaSS for the preparation of seed particles was decreased to increase the molecular weight of $\mathrm{P}(\mathrm{S}-\mathrm{NaSS})$. As shown in Figure 6, the molecular weight of $\mathrm{P}(\mathrm{S}-\mathrm{NaSS})$ in $\mathrm{PS} / \mathrm{P}(\mathrm{S}-\mathrm{NaSS})_{1 / 0.1}$ seed particles was increased with decreasing initiator concentration. The hydrophilicities of seed particle surfaces were the same, which was confirmed using the gel-trapping method.

Figure 7 shows SEM photographs of $\mathrm{PS} / \mathrm{P}(\mathrm{S}-\mathrm{NaSS}) / \mathrm{P} n$-BMA composite particles prepared by SDPs of $n$-BMA with $\mathrm{PS} / \mathrm{P}(\mathrm{S}-\mathrm{NaSS})_{1 / 0.1}$ (S-NaSS $=80-20, \quad \mathrm{~W}-\mathrm{w})$ seed particles having various molecular weights of $\mathrm{P}(\mathrm{S}-\mathrm{NaSS})$. In cases of lower molecular weights of $\mathrm{P}(\mathrm{S}-\mathrm{NaSS}), \mathrm{PS} / \mathrm{P}(\mathrm{S}-\mathrm{NaSS}) / \mathrm{P} n$-BMA composite particles exhibited 

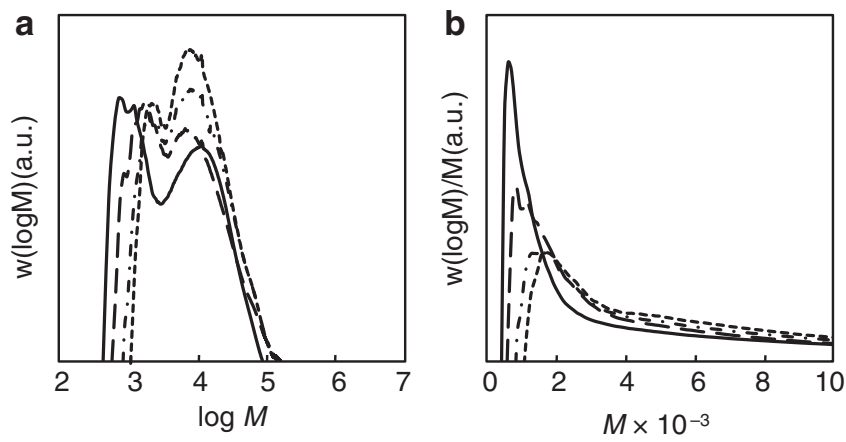

Figure 6 Molecular weight distributions (MWDs) and number distributions of $\mathrm{P}(\mathrm{S}-\mathrm{NaSS})$ in PS/P(S-NaSS) seed particles prepared at different initiator concentrations. (a) MWDs and (b) number distributions (area normalized to unity) of P(S-NaSS) in PS/P(S-NaSS $)_{1 / 0.1}$ seed particles prepared by SDPS of $\mathrm{S}$ and NaSS. S-NaSS ratios $(\mathrm{w}-\mathrm{w})=80-20$. AIBN (mmoll-1): (----) 0.055 ; (- - ) 0.11; (- -) 0.55; (-) 1.1 .
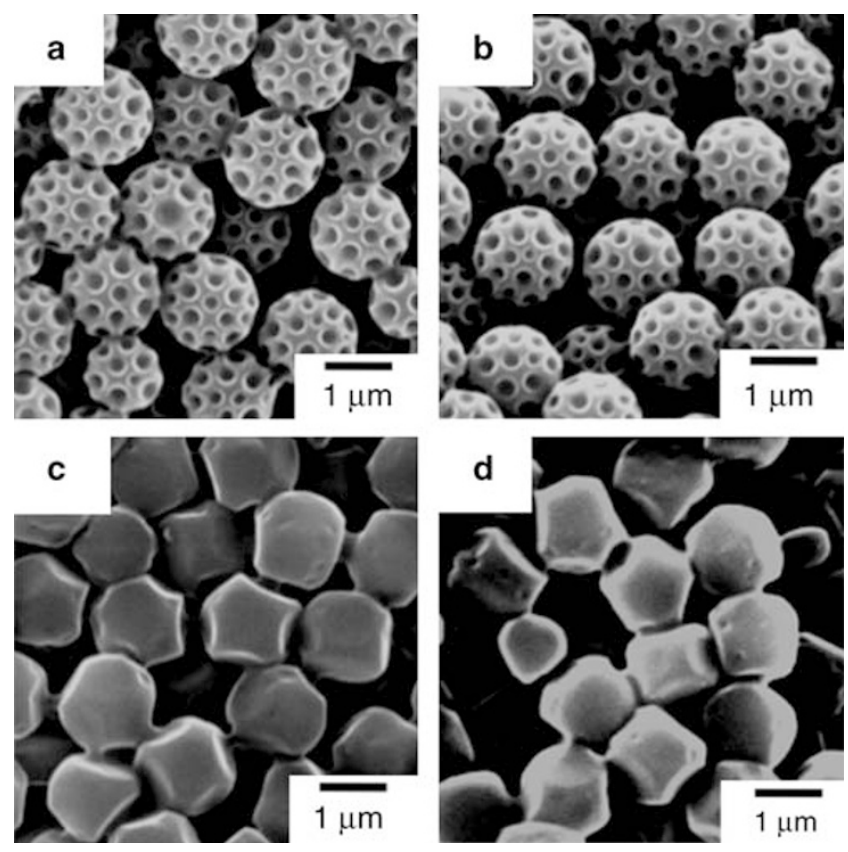

Figure 7 PS/P(S-NaSS)/Pn-BMA composite particles prepared by SDP with $\mathrm{PS} / \mathrm{P}(\mathrm{S}-\mathrm{NaSS})$ seed particles having different molecular weights of $\mathrm{P}(\mathrm{S}$ NaSS). Scanning electron microscope photographs of PS/P(S-NaSS)/PnBMA composite particles prepared by SDPs of $n$-BMA in the presence of dodecane droplets in a methanol/water $(80 / 20$, w/w) medium with different $\mathrm{PS} / \mathrm{P}(\mathrm{S}-\mathrm{NaSS})_{1 / 0.1}\left(\mathrm{~S}-\mathrm{NaSS}=80-20\right.$, w-w) seed particles. AIBN $\left(\mathrm{mmol}^{-1}\right)$ used for preparation of seed particles: (a) 0.055 ; (b) 0.11 ; (c) 0.55 ; (d) 1.1 .

polyhedral shapes (Figures $7 \mathrm{c}$ and $\mathrm{d}$ ), whereas at higher molecular weights, golf ball-like particles were obtained (Figures $7 \mathrm{a}$ and $\mathrm{b}$ ). When $\mathrm{PS} / \mathrm{P}(\mathrm{S}-\mathrm{NaSS})_{1 / 1} \quad\left(\mathrm{~S}-\mathrm{NaSS}=98-2, \mathrm{w}-\mathrm{w},[\mathrm{AIBN}]_{0} \quad\left(\mathrm{mmoll}^{-1}\right)=0.11\right)$ seed particles, the hydrophilicity of the surface and the molecular weight of which were low, were used as seed, $\mathrm{PS} / \mathrm{P}(\mathrm{S}-\mathrm{NaSS}) / \mathrm{P} n$-BMA composite particles had a similar polyhedral shape as shown in Figures $7 \mathrm{c}$ and $\mathrm{d}$. Table 3 shows the summary of the effect of $\mathrm{P}(\mathrm{S}-\mathrm{NaSS})$ molecular weight on the formation of golf ball-like particles.

From the above results, it is concluded that there are two important factors in the preparation of golf ball-like $\mathrm{PS} / \mathrm{P}(\mathrm{S}-\mathrm{NaSS}) / \mathrm{P} n$-BMA
Table 3 Effect of P(S-NaSS) molecular weight of PS/P(S-NaSS) seed particles $^{\mathrm{a}}$ on the formation of golf ball-like composite particles prepared by SDP of $n$-BMA

\begin{tabular}{lcccc}
$\begin{array}{l}P S / P \\
(S-N a S S)\end{array}$ & $1 / 1$ & $1 / 1$ & $1 / 0.1$ & $1 / 0.1$ \\
\hline S-NaSS & $98-2$ & $98-2$ & $80-20$ & $80-20$ \\
MW & High & Low & High & Low \\
$\left(M_{\mathrm{n},}, \mathrm{PDI}\right)$ & $\left(3.1 \times 10^{3}, 10.0\right)$ & $\left(1.6 \times 10^{3}, 7.5\right)$ & $\left(4.4 \times 10^{3}, 2.1\right)$ & $\left(2.0 \times 10^{3}, 2.1\right)$ \\
Structure & Golf ball & Polyhedral & Golf ball & Polyhedral \\
\hline
\end{tabular}

Abbreviations: MW, molecular weight; $n$-BMA, $n$-butyl methacrylate; PS, polystyrene; $\mathrm{P}(\mathrm{S}-\mathrm{NaSS})$, poly(styrene-co-sodium styrene sulfonate).

Summary of the effect of $\mathrm{P}$ (S-NaSS) molecular weight on the formation of golf ball-like particles.

pall PS/P(S-NaSS) seed particles had hydrophilic surfaces as shown in Figure 3.

composite particles by SDP of $n$-BMA using PS/P(S-NaSS) core/shell seed particles as follows: (1) high surface hydrophilicity of $\mathrm{P}(\mathrm{S}-\mathrm{NaSS})$ shell for the formation of several $\mathrm{P} n$-BMA domains in the shell; (2) high molecular weight of $\mathrm{P}(\mathrm{S}-\mathrm{NaSS})$ shell for preventing the coalescence of domains.

\section{CONCLUSIONS}

The effect of the hydrophilic shell thickness of seed particles on the formation of golf ball-like particles using SDP was investigated. $\mathrm{PS} / \mathrm{P}(\mathrm{S}-\mathrm{NaSS}) / \mathrm{P} n$-BMA composite particles prepared by SDP of $n$-BMA with $\mathrm{PS} / \mathrm{P}(\mathrm{S}-\mathrm{NaSS})$ core/shell seed particles having a thin hydrophilic $\mathrm{P}(\mathrm{S}-\mathrm{NaSS})$ shell in the presence of dodecane exhibited a polyhedral shape. When composite particles were prepared using PS/ $\mathrm{P}(\mathrm{S}-\mathrm{NaSS})$ core/shell seed particles having a thin shell with high molecular weight, golf ball-like particles were successfully obtained. These results indicate that golf ball-like particles were prepared only when the following two conditions were fulfilled: (1) the shell polymer $(\mathrm{P}(\mathrm{S}-\mathrm{NaSS}))$ in seed particles has a stronger affinity to the medium than does the polymer (Pn-BMA) prepared by SDP; (2) the shell polymer has low mobility (high molecular weight).

\section{ACKNOWLEDGEMENTS}

This study was supported by Grant-in-Aid for Scientific Research (Grant 21245050) from the Japan Society for the Promotion of Science (JSPS).

1 Yin, Y. \& Xia, Y. Self-assembly of monodispersed spherical colloids into complex aggregates with well-defined sizes, shapes, and structures. Adv. Mater. 13, 267-271 (2001).

2 Dullens, R. P. A., Mourad, M. C. D., Aarts, D. G. A. L., Hoogenboom, J. P. \& Kegel, W. K. Shape-induced frustration of hexagonal order in polyhederal colloids. Phys. Rev. Lett. 96, 028304 (2006)

3 Mischenko, M. I., Hovenier, J. W. \& Travis, L. D. Light Scattering by Nonspherical Particles: Theory, Mesurements, Applications, Academic Press: San Diego, (2000).

4 Jogun, S.M. \& Zukoski, C.F. Reology and microstructure of dense suspensions of plate-shaped colloidal particles. J. Rheol. 43, 847-871 (1999).

5 Matsumoto, T., Okubo, M. \& Shibao, S. Formation mechanism of heterogeneous structure in particles produced by seeded emulsion polymerization. Kobunshi Ronbunshu 33, 575-583 (1976).

6 Okubo, M., Katsuta, Y., Yamada, A. \& Matsumoto, T. Control of morphology in particles produced by seeded emulsion polymerization. Kobunshi Ronbunshu 36, 459-464 (1979).

7 Okubo, M., Ando, M., Yamada, A., Katsuta, Y. \& Matsumoto, T. Anomalous composite polymer emulsion particles with voids produced by seeded emulsion polymerization. J. Polym. Sci. Polym. Lett. Ed. 19, 143-147 (1981).

8 Okubo, M., Katsuta, Y. \& Matsumoto, T. Peculiar morphology of composite particles produced by seeded emulsion polymerization. J. Polym. Sci. Polym. Lett. Ed. 20, 45-51 (1982).

9 Cho, I. \& Lee, K.- W. Morphology of latex particles formed by poly(methyl methacrylate)seeded emulsion polymerization of styrene. J. Appl. Polym. Sci. 30, 1903-1926 (1985). 
10 Skjeltorp, A. T., Ugelstad, J. \& Ellingsen, T. Preparation of nonspherical, monodisperse polymer particles and their self-organization. J. Colloid Interface Sci. 113, 577-582 (1986).

11 Okubo, M., Kanaida, K. \& Matsumoto, T. Production of anomalously shaped carboxylated polymer particles by seeded emulsion polymerization. Colloid Polym. Sci. 265, 876-881 (1987).

12 Sheu, H. R., El-Aasser, M. S. \& Vanderhoff, J. W. Phase separation in polystyrene latex interpenetrating polymer network. J. Polym. Sci. A Polym. Chem. 28, 653-667 (1990).

13 Okubo, M., Fujiwara, T. \& Yamaguchi, A. Morphology of anomalous polystyrene/ polybutyl acrylate composite particles produced by seeded emulsion polymerization. Colloid Polym. Sci. 276, 186-189 (1998).

$14 \mathrm{Ni}, \mathrm{H} ., \mathrm{Ma}, \mathrm{G}$. , Nagai, M. \& Omi, S. Novel method of preparation of a charged mosaic membrane by using dipole-like microspheres. II. Preparation of dumbbell/egg-like microspheres. J. Appl. Polym. Sci. 80, 2002-2017 (2001).

15 Okubo, M., Wang, Z., Yamashita, T., Ise, E. \& Minami, H. Morphology of micron-sized, monomer-adsorbed, crosslinked polymer particles having snowmanlike shapes prepared by the dynamic swelling method. J. Polym. Sci. A Polym. Chem. 39, 3106-3111 (2001).

16 Stubbs, J. M. \& Sundberg, D. C. A round robin study for the characterization of latex particle morphology-multiple analytical techniques to probe specific structural features. Polymer 46, 1125-1138 (2005).

17 Kegel, W. K., Breed, D., Elsesser, M. \& Pine, D. J. Formation of anisotropic polymer colloids by disparate relaxation times. Langmuir 22, 7135-7136 (2006).

$18 \mathrm{Kim}$, J.- W., Larsen, R. J. \& Weitz, D. A. Synthesis of nonspherical colloidal particles with anisotropic properties. J. Am. Chem. Soc. 128, 14374-14377 (2006).

19 Mock, E. B., De Bruyn, H., Howkett, B. S., Gilbert, R. G. \& Zukoski, C. F. Synthesis of anisotropic nanoparticles by seeded emulsion polymerization. Langmuir 22 4037-4043 (2006).

20 Okubo, M., Miya, T., Minami, H. \& Takekoh, R. Morphology of micron-sized, monodisperse, nonspherical polystyrene/poly(n-butyl methacrylate) composite particles produced by seeded dispersion polymerization. J. Appl. Polym. Sci. 83, 2013-2021 (2002).
21 Wang, D., Dimonie, V. L., Sudol, E. D. \& El-Aasser, M. S. Seeded dispersion polymerization. J. Appl. Polym. Sci. 84, 2710-2720 (2002).

22 Okubo, M., Fujibayashi, T., Yamada, M. \& Minami, H. Micron-sized, monodisperse, snowman/confetti-shaped polymer particles by seeded dispersion polymerization. Colloid Polym. Sci. 283, 1041-1045 (2005).

23 Fujibayashi, T. \& Okubo, M. Preparation and thermodynamic stability of micron-sized, monodisperse composite polymer particles of disc-like shapes by seeded dispersion polymerization. Langmuir 23, 7958-7962 (2007).

24 Sundberg, D. C. \& Durant, Y. G. Latex particle morphology, fundamental aspects: a review. Polym. React. Eng. 11, 379-432 (2003).

25 Okubo, M., Fujibayashi, T. \& Terada, A. Synthesis of micron-sized, monodisperse polymer particles of disc-like and polyhedral shapes by seeded dispersion polymerization. Colloid Polym. Sci. 283, 793-798 (2005).

26 Fujibayashi, T., Komatsu, Y., Konishi, N., Yamori, H. \& Okubo, M. Effect of polymer polarity on the shape of 'golf ball-like' particles prepared by seeded dispersion polymerization. Ind. Eng. Chem. Res. 47, 6445-6449 (2008).

27 Paunov, V. N. Novel method for determining the three-phase contact angle of colloid particles adsorbed at air-water and oil-water interface. Langmuir 19, 7970-7976 (2003).

28 Okubo, M., Ikegami, K. \& Yamamoto, Y. Prepartion of micron-sized monodisperse polymer microspheres having chloromethyl group. Colloid Polym. Sci. 267, 193-200 (1989).

29 Okubo, M., Katayama, Y. \& Yamamoto, Y. Preparation of micron-size monodisperse polymer microspheres having crosslinked structures and vinyl groups. Colloid Polym. Sci. 269, 217-221 (1991).

30 Okubo, M., Okada, M., Miya, T. \& Takekoh, R. Production of micron-sized, monodisperse composite polymer particles having epoxy groups by seeded dispersion polymerization. Colloid Polym. Sci. 279, 807-812 (2001).

31 Gonzalez-Ortiz, L. J. \& Asua, J. M. Development of particle morphology in emulsion polymerization. 1. Cluster dynamics. Macromolecules 28, 3135-3145 (1995).

32 Gonzalez-Ortiz, L. J. \& Asua, J. M. Development of particle morphology in emulsion polymerization. 3. Cluster nucleation and dynamics in polymerizing systems. Macromolecules 29, 4520-4527 (1996).

33 Sundberg, D. C. \& Durant, Y. G. Latex particle morphology, fundamental aspects: a review. Polym. React. Eng. 11, 379-432 (2003). 